\title{
A test of the independence of the approach and avoidance gradients ${ }^{1}$
}

W. KIRK RICHARDSON AND JOHN W. DONAHOE UNIVERSITY OF KENTUCKY

Varying the correlation between aversive and appetitive events produced by the terminal response of an FR conflict chain was found to alter the amount of response suppression during conflict but not the shape of the conflict gradient. These findings are inconsistent with the assumption of the independence of approach and avoidance gradients in conflict theory in so far as gradient height is concerned but support the theory in the more important aspect of gradient shape.

The purpose of this experiment was to evaluate the assumption in conflict theory that the gradients of approach and avoidance are independent (Anderson, 1962; Miller, 1959). According to the assumption of independence of gradients, a trial terminating in an aversive event (e.g., electric shock) is a reinforced trial for avoidance independent of the cooccurrence of an appetitive event. Similarly, a trial terminating in an appetitive event (e.g., food) is a reinforced trial for approach independent of the cooccurrence of an aversive event. Williams \& Barry (1966) have found, however, that the barpressing performance of a group of rats receiving unpaired shocks and food on a variable-interval reinforcement schedule was more suppressed than when the same animals received paired shocks and food. As a consequence, these investigators rejected the assumption of independence of gradients. Because a free-responding situation was employed rather than a discrete-trial situation, no assessment of the effect of shock-food pairings on the shape of the conflict gradient was possible, and it is therefore unclear whether both the shapes and heights of the approach and avoidance gradients or only the heights are nonindependent. Accordingly, the present experiment evaluated the assumption of the independence of the gradients using a procedure which permitted an analysis of the effects of shock-food pairings on both the shape and the height of the conflict gradient. Method

Thirty-six 110 day old, male, albino rats maintained at $80 \%$ of free-feeding weight served as Ss.

Four identically constructed operant chambers were used, each chamber having a response bar, a pilot lamp 3 in. over the bar, and a foodcup. The chambers were enclosed within sound-attenuating hulls with blowers to provide ventilation and with an $85 \mathrm{~dB}$ white noise masking stimulus. The grid floor, bar, and foodcup could be electrified via a GrasonStadler shock source and scrambler. Experimental events were controlled and responses were monitored by timing and switching circuits located in an adjacent room.
Following adaptation to the laboratory and institution of the deprivation schedule. Ss were given two days of feeder training and three days of continuous reinforcement (50 45-mg pellets per day) with the pilot light at the same intensity which subsequently prevailed during reinforcement on FR trials. A $50 \%$ random reinforcement, FR-10 schedule was then administered for 21 days with 20 FR trials being given each day. For all Ss, the intensity of the pilot lamp increased in equal $\log -\log$ steps from 3 to $20 \mathrm{ft}-\mathrm{c}$ with each response within the FR trial. During the intertrial interval, the chamber was dark and a response postponed the onset of the next FR trial for $t$ sec. The value of $t$ was gradually increased from 10 to $30 \mathrm{sec}$ during the first five days of training. Ss were randomly subdivided into three groups of $12 \mathrm{Ss}$ each: (a) a control group which continued to receive food on a random half of the FR trials (C group); (b) a conflict group in which the occurrence of food and shock were perfectly, positively correlated in that shock was immediately produced by the terminal response of all reinforced trials ( +1 group); and (c) a conflict group in which the occurrence of food and shock were perfectly, negatively correlated in that shock was produced by the terminal response of all nonreinforced trials ( -1 group). Following approach training, the +1 and -1 groups were given 21 days of conflict training, seven days each at shock intensities of $.1, .2$, and $.3 \mathrm{~mA}$. Group $\mathrm{C}$ received an additional 21 days of approach training.

Performance was measured by speed scores determined from the reciprocal of the latency of each of the 10 responses within the FR trial.

Results

Prior to intergroup comparisons of conflict performance, it was necessary to determine whether equality of approach behavior had been achieved. At the completion of the initial 21 days of approach training, the heights and shapes of the gradients obtained from the $+1,-1$, and $C$ groups were nonsignificantly different $(p>.10$ for both height and shape). Further evidence for the stable nature of the approach gradients was provided by the lack of change in the height or shape of the Group $C$ gradient after an additional 21 days of training ( $p>.20$ for both height and shape).

The effect of shock on the heights of the conflict gradients of the +1 and -1 groups, together with the height of the approach gradient of Group $C$ after a comparable amount of training, is shown in Fig. 1. The height of the -1 conflict gradient was progres- 


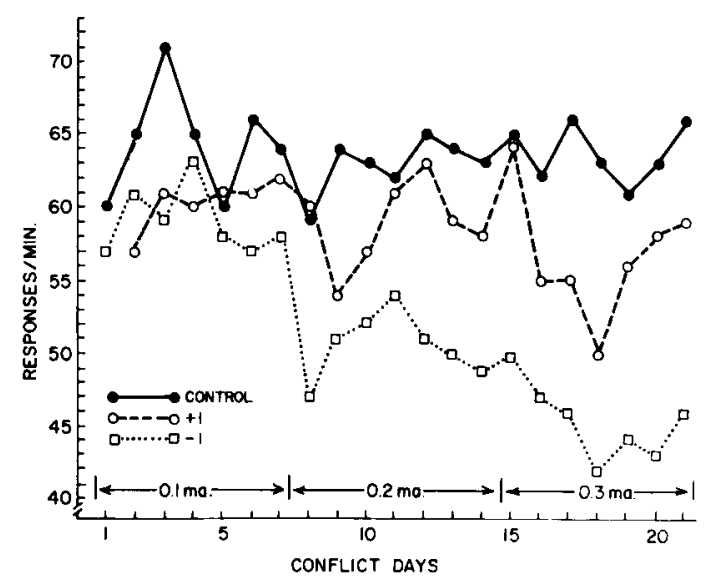

Fig. 1. Effect of the shock-food correlation and shock intensity on the height of the conflict gradient.

sively depressed as a function of increased shock intensity, while the height of the +1 conflict gradient differed little from that of the $\mathrm{C}$ approach gradient. Statistical analysis of total speed indicated the presence of a signiffcant groups by shock intensity interaction when the +1 and $C$ groups were compared with the -1 group $(F=4.44, \mathrm{df}=1 / 64, \mathrm{p}<.05)$. At .3 $\mathrm{mA}$ shock intensity, performance of the -1 group was suppressed below that of the +1 and $C$ groups $(p<.001)$, while the performance of the +1 and $C$ groups did not differ. As measured by starting speed (the reciprocal of the latency of the first response of the FR trial), the same findings were obtained except that the interaction effect and all intergroup comparisons at $.3 \mathrm{~mA}$ were reliable at the .01 level.

Figure 2 contains the conflict gradients for the +1 and -1 groups at $.3 \mathrm{~mA}$ shock intensity, and the ap-

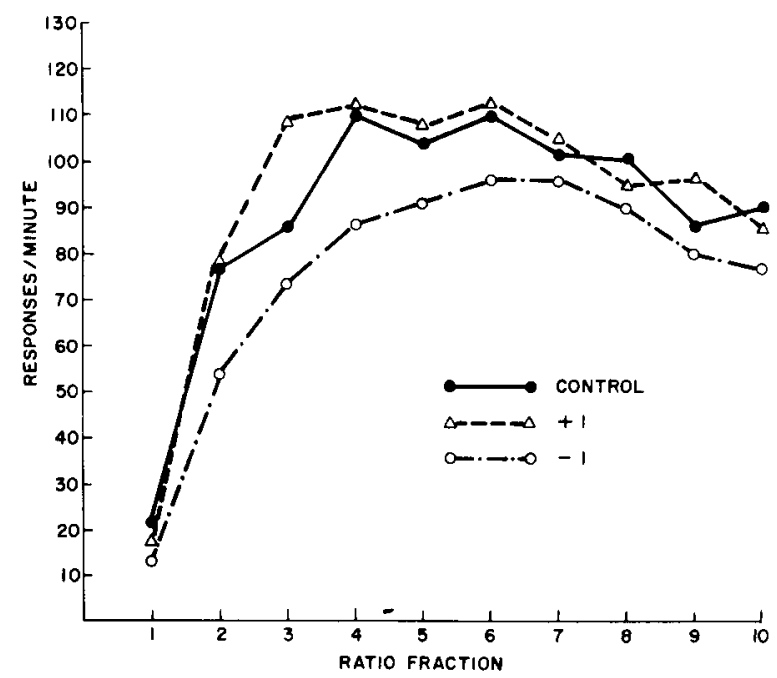

Fig. 2. Effect of the shock-food correlation on the shape of the $.3 \mathrm{~mA}$ conflict gradient. proach gradient for Group $C$ after the same number of training trials. Although the maximum difference in the heights of the gradients was observed at .3 $\mathrm{mA}$ intensity, no differences in the shapes of the gradients were found at this or any other shock intensity $(p>.20)$.

\section{Discussion}

The finding that variations in the shock-food correlation affected the height of the conflict gradient is consistent with the work of Williams \& Barry (1966) and others (Melvin \& Brown, 1964; Murray \& Nevin, 1967) in indicating that the suppressing effects of an aversive stimulus may be reduced if that stimulus is paired with food. In contrast, the finding that variations in the shock-food correlation did not differentially affect the shapes of the conflict gradients indicates that the shapes of the approach and avoidance gradients were independent. As the majority of predictions uniquely derivable from conflict theory arise from assumptions regarding differences in the shapes of the approach and avoidance gradients, the present finding of gradient shape invariance indicates that the deductive process and consequent empirical tests associated with the theory are uncomplicated by appetitive-aversive interaction effects. It should be noted, however, that the present direct assessment of gradient shape invariance necessitated the use of a partial reinforcement procedure and that partial reinforcement and conflict theory have only recently and incompletely begun to be integrated (Amsel, 1962). Further work concerned with the interrelationships of nonreinforcement and punishment variables is required to explicate the central problem of the antecedents of inequalities in the slopes of the gradients of approach and avoidance.

\section{References}

AMSEL, A. Frustrative nonreward in partial reinforcement and discrimination learning: Some recent history and theoretical extension. Psychol Rev., 1962, 69, 306-328.

ANDERSON, N. H. On the quantification of Miller' conflict theory. Psychol. Rev., 1962, 69, 400-414.

MILLER, N. E. Liberalization of basic S-R concepts: Extension to conflict behavior, motivation, and social learning. In $S$. Koch (Ed.), Psychology: A study of a science. Vol. 2. New York: McGraw-Hill 1959.

WILLIAMS, D. R., \& BARRY, H. IIl. Counter conditioning in an operant conflict situation. J. comp. physiol. Psychol, 1966, 61, 154-156.

MELVIN, K. B., \& BROWN, J. S. Neutralization of an aversive light stimulus as a function of number of paired presentations with food. J. comp. physiol. Psychol., 1964, 58, 350-353.

MURRAY, M., \& NEVIN, J. A. Some effects of correlation between response-contingent shock and reinforcement. J. exp. A nal. Behav., $1967,10,301-309$.

Note

1. This investigation was supported by a NASA fellowship to the first author and by a USPHS research grant, MH 10706, to the secund author. Acknowledgment is made to the Computing Center, University of Kentucky for assistance in data analysis. 